\title{
HISTORIA Y MEMORIA EN LA NOVELA ESPAÑOLA DEL SIGLO XX (2000-2018)
}

\author{
Santiago Fortuño Llorens \\ Universidad Jaume I de Castellón \\ https://doi.org/10.18778/8220-195-6.31
}

\begin{abstract}
La literatura del siglo XX y XXI se caracteriza por tratar de perdedores y antihéroes, digamos que es un lugar común de la literatura contemporánea. Hoy usamos personajes más rotos y más derrotados (Montero, 2018: 7).
\end{abstract}

\section{Resumen}

La historia y la memoria, bajo la modalidad denominada autoficción, son características de la narrativa española en las dos primeras décadas del presente siglo. Este trabajo sitúa y analiza algunas novelas de este período, representativas en la trayectoria de sus autores y significativas literariamente en cuanto a los temas y tratamiento formal, a la recreación de los ámbitos y vivencias de los personajes y en su repercusión en el ámbito social.

Palabras clave: novelas españolas, siglo XXI, memoria, historia, autoficción.

La novela es el género literario que suscita mayor interés en España a juzgar por el número de lectores, también universitarios, y la atención que acapara en los medios de comunicación. Tengamos en cuenta que el número de libros publicados en España en 2016 alcanzó la cifra de 81.391. A su vez, los títulos editados por sectores en 2017 fue de ficción (novelas) 6.686, de no ficción 8.261 y 6.634 el de publicaciones infantiles y juveniles, según los informes de las consultoras de difusión de datos GFK y Nielsen. 
Resultan relevantes los premios de narrativa como el Planeta, el de la Crítica y el de Primavera de novela, etc. que marcan las tendencias y cuyos sellos editoriales concitan el seguimiento mediático y los índices de lectura. Otro premio destacable ha sido el Nadal, de prioritario prestigio salvo alguna que otra sorpresa en sus fallos anuales. Así, sobre el último Premio Nadal (2018), recaído en la novela de Alejandro Palomas (1967), Santos Sanz Villanueva escribía: "De ello sale una historia entretenida, pero no alcanzo a percibir qué meritos literarios o de otra clase guarde Un amor para merecer un galardón como el Nadal. Seguramente tendrá éxito comercial una obra sensiblera y folletinesca de fácil lectura, una novela trivial para pasar el rato". (2018: 16)

Consideración aparte merece el tema del canon literario, que lo van configurando los premios literarios, las reseñas en las revistas especializadas, las colaboraciones de escritores y críticos y las propias valoraciones académicas que consiguen que determinadas obras sean consideradas como relevantes o meramente puntuales. Tengamos en cuenta que la permanencia de muchas novelas en las librerías no supera el límite temporal de los tres meses, confundiéndose, en ocasiones, en supermercados y grandes superficies.

El cuento, que refleja aspectos individuales de la vida de los personajes, desde el tedio, mediante una visión expresionista o un tono burlón, según Martín Nogales (2011: 71) y el microrrelato, con su capacidad de sugestión, sorpresa y síntesis expresivas (Fortuño, 2011), han experimentado en estas tres últimas décadas una etapa de esplendor, como en ningún otro momento de nuestra historia literaria. En líneas muy generales, la novela española desde una tendencia existencialista, en los años cuarenta del pasado siglo, se orientó hacia una vertiente social y realista hasta llegar, con Tiempo de silencio (1961), a una narrativa de renovación formal y experimentación técnica, "novela artefacto", en la que el lenguaje ocupó un lugar principal:

Nada me parece más razonable y acuciante que la reivindicación absoluta del lenguaje literario para la novela [...] Narrar a estas alturas, en el terreno novelesco, ya no puede ser 
un contar limitado, a la busca de meros efectos de acción o de divagación, sino un contar integrado en un lenguaje no exclusivamente vicario y servil, sino sustantivo, que al emplearlo -siempre hacia el límite de su expresividad- logre su auténtica autonomía (Mateo Díez, 1985).

Siguió a ésta la denominada narrativa de la épica de lo cotidiano o vuelta a lo íntimo y personal, con una preocupación por lo inmediato, ahormada con una estructura clásica, "una narrativa más light -la novela de sofá, como ha dado en llamarse- de más fácil lectura y, por tanto, más de público" (Goytisolo, 2016). Por su parte, el realismo crítico y la fantasía, en su vertiente de la distopía, el cosmopolitismo y la hibridez genérica son algunas de las peculiaridades narrativas más destacables en estas dos últimas décadas. La importancia de la historia y la autoficción (aspectos en los que voy a centrarme más adelante) en la diégesis se inscriben en esta preocupación por inventariar lo personal y memorialístico al situar lo individual en su contexto vital:

Tanto el texto como el lector saben que la literatura no se percibe como un medio de redención de un mundo que ha perdido su interés en lo magno. La aspiración a lo grande aparece como un gesto fútil, una fijación en temas trascendentes y absolutos que no se corresponde con la naturaleza parcelada de la nueva realidad cultural. (Gonzalo Navajas, 1993: 116)

La mujer y su escritura han irrumpido con fuerza en la novela del siglo XX. Resultan sorprendentes hoy las consideraciones que encontrábamos, en la década de los ochenta y noventa del siglo pasado, acerca de la especificidad de la escritura de la mujer y su lugar en la novela:

pueden sorprender las inmensas posibilidades que se abren a la crítica feminista al plantearse, por ejemplo, cuál es el tratamiento que recibe la mujer en la novela contemporánea, o la consideración que mereció tiempo atrás la figura de la escritora, o bien poder releer las obras del pasado [...] para 
comprender los contextos históricos de las que surgieron. [...] La crítica feminista ha venido para quedarse como una herramienta analítica más a la hora de leer e interpretar la obra de arte. (Caballé, 2018: 14)

En una primera aproximación, debemos considerar que en el género novelístico encontramos dos grandes subgrupos: los best sellers y los excluidos de esta clasificación. Aquellos responden a una tipología reiterativa, con personajes carentes de hondura humana pero orientada comercialmente, cuya temática principal es la historia:

En el best seller el autor suprime lo indirecto, complejo o incómodo que pueda generarse con la propia escritura. Un libro literario siempre es una reconstrucción fallida, una pieza de nuestro puzle personal e inacabable. [...] El best seller es redactado en un estilo transparente -salteado con alguna palabra rebuscada como un apellido de rancio abolengo que pueda emparentarlo con un antepasado literario- para que palabras, acciones y personajes sean de un modo radical [...] El estilo, por lo general, es tan plano que las páginas se limitan al "de qué va” (Zanón, 2017).

Otro tanto ocurre en la novela negra, que en España tuvo a M. Vázquez Montalbán, Eduardo Mendoza, recordemos La verdad sobre el caso Savolta (1975), y Juan Madrid como sus iniciadores, en el siglo pasado y que hoy goza de atención en congresos y premios literarios.

Al respecto, se advierte una tensión entre una "literatura fuerte”, según la fórmula de J.A. González Sainz, y una literatura para el consumo (Sanz Villanueva, 2011: 146) o en "la convivencia no conflictiva de varias tendencias y estilos. [...] por así decirlo, la novela española se ha ido haciendo progresivamente menos castiza" (Pozuelo, 2011: 92) por encima de generaciones y marbetes clasificatorios.

Últimamente, se ha abierto camino otra clasificación aplicable más allá de la novela propiamente: alta y baja literatura. La 
clasificación se debe a José $\mathrm{M}^{\mathrm{a}}$. Guelbenzu, quien, en el Congreso de Panamá en octubre de 2013, afirmó que en España solo hay 10.000 lectores de alta literatura que es

para mí, aquella que corre cualquier clase de riesgo con la intención de hacer avanzar el arte de la escritura y de la expresión. El resto es literatura a secas, literatura que transita por caminos trillados, pudiendo ofrecer libros excelentes o menos excelentes, pero en todo caso convencionales. (Guelbenzu, 2014)

En las postrimerías del siglo XX, en "Muertes y porvenir de la novela", Luis Mateo Díez defendía que "la novela es un reto necesario, sin arte tenemos la vida echada a perder, ya que una parte crucial de la misma sólo se alcanza desde la intensidad que proporciona el arte, en esa otra realidad que fabrica la novela, la que está en lo imaginario" (1999: 23). Luis Goytisolo apuntaba los momentos de incertidumbre en los que se debatía la novela del siglo XXI:

Hablar de muerte de la novela no tiene otro valor que el de una metáfora. [...] En diversas ocasiones he señalado que, a consecuencia de los hábitos sociales que genera Internet -más profundos que los que en su día pudo generar la imprenta-, la novela ha de experimentar tarde o temprano una fuerte mutación, dar paso a una nueva forma de relato cuyas características sería inútil pretender adivinar. Tanto más cuanto que hasta el momento, si bien debilitada, la novela no presenta ningún síntoma de cambio radical (Goytisolo, L. 2016).

Vieja y nueva cuestión en la que participó, a principios del siglo XX, Ortega y Gasset quien diagnosticaba:

En suma, creo que el género novela, si no está irremediablemente agotado, se halla, de cierto, en su periodo último y padece una tal penuria de temas posibles, que el escritor necesita compensarla con la exquisita calidad de los demás ingredientes necesarios para integrar un cuerpo de novela. [...] Como 
producción genérica correcta, como mina explotable, cabe sospechar que la novela ha concluido. Las grandes venas someras, abiertas a todo esfuerzo laborioso, se han agotado. Pero quedan los filones secretos, las arriesgadas exploraciones en lo profundo, donde, acaso, yacen los cristales mejores. (Ortega y Gasset, 1925, 1975: 155 y 197)

apuntando la solución: "La materia de la novela es propiamente psicología imaginaria” (Ideas sobre la novela, 1924-1925; 1975: 197).

De esta suerte, Sonsoles Ónega (1975) reconoce que, en Después del amor (Premio de Novela Fernando Lara, 2017), relato romántico con la guerra y posguerra como escenarios, le vino fenomenal Google Earth como reconstrucción de los itinerarios de los personajes al ofrecer el lenguaje global de la informática nuevas posibilidades a la literatura y sus géneros.

En su Discurso con motivo de la concesión de doctor honoris causa por la Universidad de Salamanca, el 17 de septiembre de 2015, Mario Vargas Llosa reflexionaba acerca de estas tres preguntas: el porqué se escribe literatura, para qué sirve la literatura y cómo se escribe una novela y a esta última respondía:

Los temas me eligen a mí: escribo sobre ciertas cosas porque me han ocurrido ciertas experiencias [...] Por eso digo que las novelas que yo he escrito tienen unos temas que en cierta forma me han sido impuestos por la experiencia, por una experiencia que seguramente afecta un núcleo básico que está allí, sumergido en la parte más oscura de mi personalidad y que es, como es el caso de muchos escritores, la fuente de la vocación y de la inspiración. [...] Los temas me son impuestos por una realidad. [...] Una misma historia se podría contar de decenas o cientos de maneras diferentes, pero hay una, indudablemente, que es la mejor manera de contarla. ¿Qué quiere decir la mejor manera de contarla? La manera más persuasiva, la manera que puede aprovechar mejor las vivencias implícitas en esos personajes, en esa situación, en el ambiente que la historia refiere. 
El periodo de la historia de la novela española, que aquí abordamos, se circunscribe en el contexto histórico-social entre el principio del siglo XXI, más concretamente y para fijar fechas relevantes, el atentado terrorista del 11 M de 2004 en Madrid, que trajo consigo consecuencias políticas y sociales, y el problema del independentismo catalán, con el referéndum del 1 de octubre de 2017, que ha enfrentado a una parte de España de Cataluña, con consecuencias aún imprevisibles. Otros fenómenos sociales ofrecen temas en la reciente narrativa: la visibilización de la mujer en los más diversos campos, la Ley de la Memoria Histórica (2007) que pretende reconocer y compensar al bando de los vencidos en la guerra civil de 1936-1939, la corrupción política, la burbuja inmobiliaria, la inmigración, el fenómeno de los millenial...

\section{La historia en la novela española del siglo XXI}

En la novela española actual, que acotaré, por precisión cronológica, a aquellas novelas aparecidas en este siglo, voy a centrarme, como ya he adelantado, en dos aspectos: el tratamiento de la historia reciente o no y el de la memoria. El contar, evocar o revivir la historia tiene ya una larga tradición narrativa. La novela del siglo XIX dio muestras destacadas, acrecentadas en la actualidad en sus variedades técnicas, y como escribiera Ricardo Gullón al referirse a los Episodios nacionales de Pérez Galdós:

mirando con atención la textura narrativa se descubren en ella ambos elementos: lo histórico como materia integrante de la novela; lo imaginativo, como agente transformador de esa materia en sustancia novelesca. [...] No solamente contará la Historia como testigo sino como héroe o protagonista -es decir, personalizándola-, con la variedad de "posturas o disfraces» que crea conveniente introducir, puesto que así tendrá la obra mayor encanto. (Gullón, 1970: 2-6)

El novelista amplía el campo de acción del historiador prestando mayor libertad imaginativa, "para eso sirve la ficción, para llegar a donde no se puede de ninguna otra manera, al otro lado del espejo, al interior de esa cámara sellada que es siempre la 
conciencia de otra persona" (Gullón, 1970), teniendo en cuenta que "La verdad de la literatura es una verdad moral, abstracta, universal, una verdad que busca fijar lo que les pasa a todos los hombres en cualquier momento y lugar" (Cercas, 2011). Soldados de Salamina (2001) de Javier Cercas (1962) marcó un hito en la novela histórica. El narrador heterodiegético, a su vez autor implícito, describe a Rafael Sánchez Mazas "el primer fascista de España, y muy exacto decir que fue su más influyente teórico. [...] quizá para Sánchez Mazas el fascismo no fue sino un intento político de realizar su poesía, de hacer realidad el mundo que melancólicamente evoca en ella" (2001: 82) como héroe en la novela, descrito en una escena repleta de suspense y tensión dramática:

Entonces lo ve. Está de pie junto a la hoya, alto y corpulento y recortado contra el verde oscuro de los pinos y el azul oscuro de la nueves, jadeando un poco, las manos grandes aferradas al fusil terciado y el uniforme de campaña profuso de hebillas y raído de intemperie. [...] Sánchez Mazas mira al soldado que lo va a matar o va a entregarlo [...] y lo recuerda o cree recordarlo entre los soldados harapientos que lo vigilaban en el monasterio. [...] Así loca y confusa la encendida mente, aguarda Rafael Sánchez Mazas - poeta exquisito, ideólogo fascista, futuro ministro de Franco- la descarga que ha de acabar con él. Pero la descarga no llega, y Sánchez Mazas, como si ya hubiera muerto... -¿Hay alguien por ahí?, se oye. [...]- Aquí no hay nadie! contesta el soldado. Luego da media vuelta y se va. (2001: 103-104)

Tras el doble éxito de Soldados de Salamina, fílmico en esta ocasión (2003) bajo la dirección de David Trueba, Cercas publicó Anatomía de un instante en 2009. Novela que participa de varios géneros

parece un libro de historia; también parece un ensayo; también parece una crónica, o un reportaje periodístico; a ratos parece un torbellino de biografías paralelas y contrapuestas girando en una encrucijada de la historia (Cercas, 2011: 12-13), 
constituyendo, como escribía su autor,

El centro neurálgico y la principal virtud del género: su carácter libérrimo, híbrido, casi infinitamente maleable, el hecho de que es, según decía, un género de géneros, y que se alimenta de todos [...] Balzac aspiraba a equiparar la novela a la historia, y por eso afirma famosamente que "la novela es la historia privada de las naciones”. (Cercas, 2011: 12-13)

Más próximamente, en 2017, siguió Javier Cercas, en esta misma línea narrativa con El monarca de las sombras en la que cuenta la verdad, que hasta entonces no ha podido ser contada, al presentar la historia de Manuel Mena, tío paterno de Javier Cercas y a quien el personaje narrador de la novela busca, para recuperarlo en la memoria de su pueblo natal. En ella mezcla historia y su comentario, el porqué del descargo de conciencia al alumbrarla, "que por fin iba a contar la historia que llevaba media vida sin contar, iba a contarla para contarle a mi madre la verdad de Manuel Mena" (2017: 276):

Un monarca en el reino de las sombras, Manuel Mena, que murió "por culpa de una panda de hijos de puta que envenenaban el cerebro de los niños y los mandaban al matadero. (2017: 269)

Novela, pues, que participa de leyenda épica y de autoficción:

comprendí que escribir sobre Manuel Mena era escribir sobre mí, que su biografía era mi biografía, que sus errores y sus responsabilidades y su culpa y su vergüenza y su miseria y su muerte y sus derrotas y su espanto y su suciedad y sus lágrimas y su sacrificio y su pasión y su deshonor eran los míos [...] iba a acabar mi novela, aquel secreto transparente según el cual, aunque sea verdad que la historia la escriben los vencedores y la gente cuenta leyendas y los literatos fantasean, ni siquiera la muerte es segura (2017: 280-281). 
Arturo Pérez Reverte (1951), por su parte, en Un día de cólera (2007) recuerda a los héroes del pueblo, con sus nombres y oficios, lugares y profesiones, que resistieron un dos de mayo de 1808 en Madrid, a las embestidas de los franceses. La novela está construida con precisión realista cronológica - desde la siete de la mañana del lunes dos de mayo de 1808 a las cinco y cuatro minutos del día siguiente- y reducción simultaneística, de larga tradición en la novelística del siglo XX (Villanueva, 1977). En esta novela coral, el también periodista Pérez Reverte muestra el patriotismo popular y decepcionante, a su vez, el de los nobles y adinerados, en una estructura alternante temporal de escenas de ambos contendientes, cuyo arrojo español ya inmortalizaron Espronceda y el poeta Bernardo López García. En un afán de celo y verdad documentales, acompaña a la novela un mapa del Madrid en la fecha epónima, con amplia bibliografía de autores de distintas nacionalidades y lenguas, que desdibuja lo histórico en una obra de ficción.

Antonio Muñoz Molina (1956) en La noche de los tiempos (2009) cuenta las experiencias personales de Ignacio Abel, huido de España, al llegar a la estación de Pennsylvania, a finales de 1936 y la vida de políticos y escritores del momento como Negrín "firme y vigoroso", los asesinatos del Conde de Asalto Castillo y de Calvo Sotelo, las peripecias de Juan R. Jiménez y su mujer Zenobia, de Moreno Villa, huésped en la quietud de la Residencia de Estudiantes, y de Bergamín... entremezclados con personajes de ficción. La novela superpone historias presididas por la relación amorosa del protagonista Ignacio Abel con la escritora Judith Biely, prototipo de la nueva mujer de los años veinte, "trayendo consigo el vendaval de su novedad [...] Su misma presencia era ya un trastorno, el torbellino metódico de una puerta giratoria, la aparición que hace sonar bruscamente la campanilla de entrada..." (2009: 229) con el recuerdo de sus hijos, "la otra mitad rota de su vida" y el más tormentoso de su mujer Adela; su vida laboral en la oficina técnica de la Ciudad Universitaria y la del profesor Rossman "en su olor rancio a ropa no lavada, a pensión pobre y a enfermedad de la próstata” (2009: 109), enmarcada en ciudades-escenarios de la obra del autor de Como la sombra que se va (2014), Madrid, Nueva York y la capital lusa... El tintineo 
y el brillo cobran presencia viva en La noche de los tiempos, el estilo indirecto modula el monólogo retrospectivo y la narración rápida y trepidante de escenas superpuestas prestan a la novela un tempo rápido y sugerentes incisos y comentarios y, como en El jinete polaco (1991) de Muñoz Molina, una relación amorosa apasionada queda imbricada en la guerra civil española:

Así la estructura ramificada y poliforma del estilo está plenamente justificada por la naturaleza del empeño; se trata de decir todo lo que fue la guerra para todos. [...] la prosa de Muñoz Molina es lujuriante, y su alianza de precisión y sensorialidad resulta irresistible, casi avasalladora. El torbellino de la historia envuelve, arrastra y acarrea -como, al propio tiempo, lo hace el torbellino de la pasión amatoria- a los personajes, exactamente del mismo modo que el torbellino de la prosa se lleva en volandas al lector. (Gimferrer, 2018: 22-23)

El paratexto de Manuel Azaña, pórtico y síntesis de la novela, suena a reproche ante el horror irracional de la barbarie de la vida española: "Veo en los sucesos de España un insulto, una rebelión contra la inteligencia, un tal desate de lo zoológico y del primitivismo incivil, que las bases de mi racionalidad se estremecen".

Frente a la rigidez de la versión oficial de los libros de Historia, con mayúscula, en la que

el amor de la carne no aflora" y "las barras de carmín no afloran a las páginas de los libros. [...] el grito silencioso de dos miradas que se cruzan, la piel erizada y la casualidad inconcebible de un encuentro que parece casual, a pesar de haber sido milimétricamente planeado en una o muchas noches en blanco. (2010: 23-24),

Almudena Grandes (1960) en Inés y la alegría (2010) relata las vivencias de la Pasionaria, con cuarenta años, y sus pasiones en silencio con Francisco Antón, de veintitrés. Constituye la primera entrega de un proyecto narrativo integrado por seis novelas independientes que comparten un espíritu y una denominación 
común, destinado a un lector implícito representado al que el texto va dirigido:

«Episodios de una guerra interminable». [...] Si he querido llamarlas «episodios» ha sido para vincularlas, más allá del tiempo y de mis limitaciones, a los "Episodios nacionales" de don Benito Pérez Galdós, que para mí es, como he declarado en muchas ocasiones, el otro gran novelista -después de Cervantes- de la literatura española de todos los tiempos. [...] Inés y la alegría es, por tanto, la primera entrega de lo que pretende ser al mismo tiempo un homenaje y un acto público de amor por Galdós, y por la España que Galdós amaba, la única patria que Luis Cernuda (1902-1963) reconocía como propia, querida y necesaria, cuando escribió un espléndido poema, "Díptico español". Los episodios que yo he podido contar son historias igual de heroicas pero mucho más pequeñas, momentos significativos de la resistencia antifranquista, que integran una epopeya modesta en apariencia, gigantesca si se relaciona con su duración, y con las condiciones en las que se desarrolló. Porque abarcan, desde perspectivas muy distintas, casi cuarenta años de lucha ininterrumpida, un ejercicio permanente de rabia y de coraje en el contexto de una represión feroz. [...] Inés y la alegría cuenta la historia de la invasión del valle de Arán, una operación militar desconocida por la inmensa mayoría de los españoles que tuvo lugar efectivamente entre el 19 y el 27 de octubre de 1944 (2010: 719-721),

y conocida como la frustrada Operación Reconquista de España

La novela posee una estructura tripartita con sendos narradores: dos personajes de ficción, Inés y Galán y uno tercero, el narrador/autor en una diégesis secuencial de acontecimientos reales e históricos, "una obra de ficción inserta en la crónica de un acontecimiento histórico real” (2010: 722).

Este mismo año (2010), Manuel Vicent (1936), en Aguirre, el magnifico presenta al polifacético Jesús Aguirre, quien tras secularizarse, contrae matrimonio con la duquesa de Alba en un día de marzo de 1978. Esta relación queda enmarcada en un relato de 
tono expresionista y caricaturesco de personajes y situaciones de una época (la Transición española) de configuración sumarial o resumen en primera persona. Como valora el editor, es un "Retablo ibérico donde este personaje se refleja en los espejos deformantes del Callejón de Gato. [...] Su vida fantasmagórica, pese a ser tan real, no puede distinguirse de la ficción literaria".

Rafael Chirbes (1949-2015), autor de En la orilla (2013) es un escritor tardío que recoge en sus novelas realistas las preocupaciones de una sociedad abocada a la crisis por una política equivocada, favorecedora del boom de la construcción y perjudicial para el medio ambiente. Chirbes ya había publicado en 2007 Crematorio de la que En la orilla es continuadora y, asimismo, prolongación de la novela realista, social y comprometida de los años 50 :

la mejor novela sobre uno de los principales aspectos de la actual crisis -la burbuja inmobiliaria- que he leído. [...] monólogos interiores entrelazados sin solución de continuidad y sin la menor pretensión en distinguir entre buenos y malos. [...] Un monólogo interior [...] elaborado en un discurso coherente al modo de John Dos Passos. (Goytisolo, Babelia, 5-02-2016).

Continúa, pues, el tratamiento de los temas de la emigración, la corrupción, el sexo, la mentira, la España del despilfarro, del dinero fácil con el recuerdo de la guerra civil, de las dos Españas y, argumentalmente, la dependencia y fracaso del protagonista, Esteban, con su padre, aquejado de Alzheimer. En el capítulo final, "Éxodo", en monólogo interior entona el Ubi sunt? ante unos años de euforia económica, con evidente intencionalidad moral: “Duró lo que duró, no estuvo mal, las mil generaciones que nos preceden no tuvieron un día de su vida así, la verdad que no, y ahora nos queda el dolor de cabeza que deja la resaca”, ante el hoy más responsable: "Obviamente, vivimos menos emputecidos, vivimos desengolfados, o con resaca de golfeo. En el ambiente se palpan nuevos valores, virtudes franciscanas: [...] incluso se mira con otros ojos el pobreterío (2013: 435). En la orilla se suceden los monólogos interiores, fragmentos metanarrativos, los flujos de conciencia, las superposiciones temporales, las reflexiones sobre la 
guerra, los inmigrantes y marginados. Crematorio, trasladada al cine en 2011 con el popular actor, Pepe Sancho, como protagonista, y la adaptación teatral, en 2017, de En la orilla han cooperado, asimismo, a su alcance social.

La novela Patria (2016) de Fernando Aramburu (1959) representa, desde el punto de vista sociológico, un récord en su venta - casi 600.000 ejemplares (558.828 ejemplares para ser exactos), con unos ingresos de más de doce millones y medio de euros (12.616.217, con exactitud, en seis meses, desde su lanzamiento hasta el primer trimestre de este año, según GFK Top Ficción Trade), y en un éxito auspiciado por su publicidad (Premio de la Crítica 2016). Patria narra, en capítulos breves y en tempo rápido, los cincuenta años de violencia infligida por la banda terrorista ETA, contada por sus víctimas y las consecuencias en sus vidas en el medio rural. El argumento desencadenante, que da unidad al relato, es la historia de dos familias, en un tiempo amigas. El hijo de una de ellas, José Mari, es el asesino de Txato, marido de Bittori, y padres de Nerea y Javier. El tiempo referencial, el año anterior a la muerte de Franco (1974) y el de los actos de la Exposición Universal de Sevilla y los Juegos Olímpicos de Barcelona, ambos en 1992. El capítulo 109, "Si a la brasa le da el viento", cuenta una reunión de las Víctimas de Terrorismo y Violencia Terrorista, a la que asisten los dos hijos de Bittori en el hotel María Cristina de San Sebastián. Entre los ponentes, el juez que dictó la sentencia en el caso de su padre. Es el otro, el autor homodiegético, quien expone los objetivos que le impulsaron a escribir este libro:

Y este proyecto de componer, por medio de la ficción literaria, un testimonio de las atrocidades cometidas por la banda terrorista surge en mi caso de una doble motivación. Por un lado, la empatía que les profeso a las víctimas del terrorismo. Por otro, el rechazo sin paliativos que me suscitan la violencia y cualesquiera agresiones dirigidas contra el Estado de Derecho. [...] A fin de cuentas yo también fui un adolescente vasco expuesto como tantos otros chavales de mi época a la propaganda favorecedora del terrorismo y de la doctrina en que este se fundamenta (2016: 551). 
Citemos, finalmente, No cantaremos en tierra de extraños (2016) de Ernesto Pérez Zúñiga (1971). Novela que cuenta cómo a finales de 1944, dos españoles exiliados españoles se encuentran en un hospital de Toulouse y deciden retornar a la España franquista en busca de la mujer de uno de ellos. Como La noche de los tiempos es, simultáneamente, una historia testimonial y de amor. Una novela sobre la posguerra, la construcción de la democracia y los héroes que lucharon contra el totalitarismo. (El País, 17-01-2017).

\section{Memoria. Autoficción}

La literatura española tiene en su haber múltiples ejemplos de pudor e inhibición personales por parte de sus autores, frente a la anglosajona donde existe una tradición de memorias y autobiografías. Así lo apuntaba Carlos Bousoño al circunscribirlo al pudor sentimental en la poesía española. La autoficción ha sido definida como "un dispositivo muy simple: sea un relato, cuyo autor, narrador y protagonista comparten la misma identidad nominal y cuya clasificación genérica indica que se trata de una novela" (Lecarme, 1994: 227) o "es una obra literaria por la cual un escritor se inventa una personalidad y una existencia, conservando su identidad real" (Colonna, 2004). Manuel Alberca cita 63 novelas autoficcionales españolas e hispanoamericanas entre los años 2000 y 2007 :

A partir de los años 70 del pasado siglo se produjo una extraordinaria expansión de la literatura autobiográfica en todas las literaturas occidentales. [...] En España esta eclosión coincidió con el final del franquismo, con el comienzo de la transición democrática. [...] Justamente la autoficción se ofrece con plena conciencia del carácter ficticio del yo y, por tanto, aunque allí se hable de la propia existencia del autor, en principio no es prioritario ni representa una exigencia delimitar la veracidad autobiográfica ya que el texto se produce simultáneamente como ficticio y real" (Alberca, 2007: 32-33)

añadiendo que "la autoficción es un género híbrido que tiende a difuminar los géneros gracias a plantear la identificación 
problemática entre el autor empírico y su representación textual" (Alberca, 2017: 325).

Manuel Vilas (1962), autor de otro de los éxitos autoficcionales con su novela Ordesa en 2018, explicaba el motivo de esta tipología literaria:

El pudor es inevitable en países sin libertades. Pero en países democráticos y occidentales, el pudor ocurre más en la mente de los escritores que en la de los lectores. [...] Porque el temblor de la confesión sigue conservando ese lujo ancestral de la verdad, o del teatro de la verdad. [...] La autoficción no tiene problemas con el pudor, porque se sigue basando en lo imaginario. [...] Un libro inaugural en la doma del pudor fue Coto vedado (1985) de Juan Goytisolo. (2018:2)

Juan Gabriel Vásquez, al valorar la prosa de Javier Marías (premio de la Crítica 2018 por Berta Isla) y exponer la relación del autor y su personalidad, recalca la función de la literatura como forma de conocimiento del propio sujeto enunciante:

"Frente a esa idea de la novela como una forma de conocimiento, yo la veo como una forma de reconocimiento", me dijo Marías una vez [...] cuya clarividencia me ha recordado una vez más por qué la ficción, en manos de sus mejores practicantes, sigue siendo la única forma que tenemos los seres humanos de conocernos cabalmente: en todas nuestras dimensiones, con todos nuestros misterios y secretos, a través de todos nuestros velos (2017: 3).

A Serge Doubrovsky se le atribuye el término autoficción (1977) para definir su relato Fils como "una ficción de acontecimientos estrictamente reales", protagonizada por él mismo. A su vez, los estudios de Philippe Lejeune, Le pacte autobiografique (1975) y El pacto ambiguo (2007) de Manuel Alberca han contribuido a crear una aproximación teórica conceptual. Este último, en su reciente libro La máscara o la vida. De la autoficción a la 
antificción (2018) va más allá al deslindar la autoficción como "la forma adolescente que eligió la autobiografía para reinventarse en los años 90, y las antificciones son la primera forma madura y original de la autobiografía en este siglo XXI" (Mora, 2018: 27):

El propio Doubrovski reconoce estar sorprendido de la fortuna de su ocurrencia. Confiesa que cuando utilizó el término por primera vez para definir Fils (1977) ni pretendía crear un nuevo género literario ni pensaba que se convertiría en un movimiento importante en la literatura francesa y mundial (Chemin, 2013). Por otra parte, los estudios genéticos de Isabelle Grell sobre el manuscrito, titulado Le Monstre, que daría lugar a Fils, han mostrado que el neologismo auto-fiction, escrito así con guión, estaba ya presente en varias ocasiones antes en las más de dos mil páginas del borrador. La primera aparición del término se produjo cuando el narrador releía un cuaderno, donde anotaba sus sueños, en los atascos de los accesos a Manhattan. Parado el tráfico, el autor aprovechaba para anotar en dicho cuaderno: «...si escribo en mi coche mi autobiografía, será mi AUTO-FICCIÓN» (Grell, 2007). Es decir, la autoficción no sería otra cosa que la ficción del coche. Por lo tanto la denominación tiene mucho de azar, es una ocurrencia en realidad, cuya traducción literal la devuelve casi a un hallazgo chistoso. (Alberca, 2017: 309-310)

Este tipo de relatos de autoficción no es nuevo y ha suscitado siempre interés. Así, en un manual de Literatura Universal (editorial Edelvives, 1958), con el preceptivo permiso de la época, el Nihil obstat del obispo de Zaragoza, se encuentra esta apostilla al Diario de un testigo de la guerra de África (1859) de Pedro A. de Alarcón: "Tanto entusiasmo despertó esta obra que dicen recibió su autor 20.000 cartas de felicitación por ella” (1958: 387).

Agustín Fernández Mallo (1967), promotor de la efímera generación Nocilla a principios del siglo XXI, epónima de su trilogía Nocilla Project, mostró recientemente su escepticismo ante el éxito de esta denominación: 
En primer lugar, creo que toda narración, y por muy aparentemente alejada que sea el espacio y el tiempo del yo, siempre es autoficción. Solo podemos escribir acerca de lo que está dentro de cada uno de nosotros como individualidad, el resto son extrapolaciones estadísticas. [...] De lo que sí descreo es de la autoficción como vómito de emociones en bruto y explícita terapia para el autor y la autora” (Fernández Mallo, 2018)

Muestras de antificción (en la que se expresa la voluntad de cumplir con el 'pacto autobiográfico', es decir, "el biógrafo afirma su sinceridad y su intención de decir la verdad, aun cuando sus promesas carezcan de futuro" (May, 1979: 417) son dos de las novelas más conocidas de Marta Sanz (1967), quien afirmará acerca de la novela actual que "Los personajes femeninos del siglo XXI dejan de ser partenaire del galán. [...] tienen vello púbico y vagina -dentata o no-, y bracean para despegarse de la ejemplaridad" (2018: 14). Más, en concreto, su novela La lección de anatomía (2008) con título homónimo del cuadro del holandés Rembrandt,

pertenece a la corriente de novela autobiográfica o familiar (Carmen Laforet, Ana María Matute, Carmen Martín Gaite, Soledad Puértolas, Marcos Giralt...) [...] Yo la calificaría de novela de autodefinición, centrada en esa necesidad de objetivarse ante uno mismo propio de la adolescencia... [...] Y es que cuando el relato, más que limitarse a exponer una sucesión de acontecimientos y experiencias, consigue crear, gracias a la capacidad evocativa de la frase, una realidad autónoma, desvinculada de todo referente, nos encontramos ante una novela, aunque la protagonista se llame Marta. (Goytisolo, Babelia, 5-02-2016).

y en donde la autora "traza, en primera persona y bajo su nombre propio la cartografía de su cuerpo a través del relato de su nacimiento". Su otra novela Clavícula (2017) es "en muchos sentidos una secuela, continuación y ampliación de la misma manera de pasar revista a su biografía a partir del propio cuerpo, de sus fragilidades y miserias, del dolor y el sufrimiento y de la enfermedad" (Alberca, 2017: 324-326). 
En Dublinesca (2010), el escritor barcelonés Enrique Vila-Matas (1948) transfiere a Samuel Riba, figuración de un conocido editor español, trazos de la propia peripecia vital del novelista: la casa de sus padres en una conocida calle de Barcelona, su enfermedad renal, su viaje a Dublín con motivo del Bloomsday el 16 de junio... Dublinesca narra el viaje a la capital irlandesa del protagonista, en compañía de otros tres amigos escritores, reticentes a los best-seller góticos y a la influencia de internet. Fundan la orden Finnegans, nombre de un pub dublinés, para conmemorar el Ulysses de James Joyce. Participa la novela, repleta de tono irónico y de parodia, del ensayismo: "la novela dublinesca por excelencia, y una de las cumbres de la imprenta, de la galaxia Gutemberg, la galaxia cuyo ocaso le está tocando vivir de lleno" (2010: 25), dirá el protagonista a sus padres. Se trata de difuminar lo autobiográfico de la fábula narrativa: "El caso es situar al lector en un lugar donde la frontera entre lo imaginado e inventado y lo vivido acaba siendo tan difusa que los hace indistintos e indistinguibles" (Pozuelo, 2017: 202).

Es otra escritora, Carme Riera (1948), quien, con una larga y galardonada trayectoria de narradora, $-T e$ dejo, amor, en prenda el mar (1975) constituyó un hito exitoso- cuenta con nostalgia su infancia en Palma de Mallorca, desde la mirada de una niña en los años de la posguerra. La transformación de su geografía natal la plasma, asimismo, con un título de claras resonancias literarias, en Tiempo de inocencia (2013).

Antonio Muñoz Molina (1956) en Ventanas de Manhattan (2004) presenta una guía turística, a la par que un libro de viaje, por las calles de Nueva York, enmarcada en un tiempo referencial relevante: el ataque terrorista a las Torres Gemelas en septiembre de 2001. Los barrios céntricos y periféricos, la sociedad multicultural, étnica y lingüística conforman el personaje central de la novela. El autor consigue, mediante sus descripciones, la incorporación del protagonista/narrador homodiegético en sus recuerdos, reflexiones y experiencias al tiempo que nos presenta viva y trepidante la actividad de la ciudad de los rascacielos. Todo lo que era sólido, su ensayo testimonial sobre la crisis reciente en el ámbito mundial y, más concretamente, en España a partir del 
año 2007, antecede en un año a Como la sombra que se va (2014), relato con un triple argumento: la huida del asesino de Martín Lutero King, James Earl Ray a Lisboa, camino de Angola en 1968; el viaje a la ciudad portuguesa del propio autor en 1987, cuando está escribiendo El invierno en Lisboa y un tercer periplo en el propio tiempo del discurso, acompañado de sus hijos. El escritor se pertrecha de datos y documentos sobre el asesino y su víctima pero la autoficción se impone por los recuerdos, con motivo de los paseos por lugares reconocidos del ayer, superpuestos a la actualidad del narrador. Es una novela repleta de encabalgamientos temporales y espaciales desde el yo homodiegético, al mismo tiempo cronista y protagonista, que enhebra tiempos y lugares desde el horizonte del hoy.

El mundo (2007) de Juan José Millás (1946), consta de cuatro partes ("El frío" de una familia de nueve hermanos, "La calle" del barrio madrileño de La Prosperidad, "Tú no eres interesante para mí", "La academia" y un epílogo). En esta novela de aprendizaje, Bildungsroman, la figura central es el artista en su evolución y destino, con el simbólico hecho de arrojar en las playas de Valencia las cenizas de sus padres. El motivo recurrente del bisturí es su propia labor literaria, que, al mismo tiempo, cura, daña y le ayuda a observar y a reconocer las calles del mundo en donde cada objeto alcanza su función. El mundo, autoficción del escritor valenciano, enlaza lo verosímil con lo novelesco, lo cotidiano con lo simbólico y muestra cuán complejos son el ser humano y la realidad que lo envuelve al desvelar lo extraordinario en lo cotidiano y lo trascendente en lo trivial y anodino.

Luis Landero (1948) en El balcón en invierno (2014) rinde homenaje a las generaciones españolas que han sufrido la guerra, la postguerra y la España de la emigración del 60 recuperando nostálgicamente el viejo tópico del elogio de la aldea y el menosprecio de lo urbano. La muerte del padre del autor constituyó el acontecimiento germinal de su vida que alumbrará "ciego e incontenible" su destino (p. 88). En este relato se da la ruptura temporal desde la memoria, el psicologismo mediante la alternancia de la prolepsis y el flash back, del estilo directo confesional con el indirecto libre o narrativo, el contrapunto y la metaliteratura: "En los libros 
leídos está la sombra, el rastro de lo que fuimos, [...] construimos nuestro modo de ser y de sentir, y lo más valioso y secreto de nuestro bagaje cultural" (2014: 115). El capítulo tercero "Ningún libro en ninguna casa. Hacia 1950" construye una biografía escenificada, con estructura asimétrica y alternancia de personas gramaticales, bajo el pretexto de que

A veces me pregunto por qué caminos, por qué atajos, por qué oscuros designios del azar he llegado yo a ser escritor. [...] Y en ninguna de las casas de unos o de otros, de toda aquella intrincada parentela, había libros. Ningún libro en ninguna casa. Tampoco leían periódicos, ni escuchaban las noticias de la radio los que tenían radio, y vivían al margen de la actualidad". (2014: 54).

El homoerotismo ha ofrecido, en lo que va de siglo, destacadas manifestaciones: Rafael Chirbes (1949-2015) en su novela póstuma De París a Austerlitz (2016) exhibe el tema de la relación gay, en la capital francesa, entre un joven artista, pintor, y Michel, obrero normando, figuración del propio autor de la novela. También la antificción de El amor del revés (2016) de Luigé Martín abordó el tema de la homosexualidad como elemento fundamental de la identidad personal sin tabúes ni prejuicios. Vicente Molina Foix (1946) y Luis Cremades (1962) escriben, a cuatro manos, El invitado amargo (2014), que se retrotrae, por su construcción, a la serie La novela de una hora, experiencia ideada por Eduardo Zamacois, en los años treinta del pasado siglo, consistente en que varios escritores redactaban un único relato llevado a cabo en capítulos alternativos (Santonja, 1993: 179). Sus fotografías en las primeras páginas muestran a dos hombres de desigual edad, que, a su vez, revelan el porqué del título: "Los celos son el fastidioso invitado amargo ("that sour unwelcome guest»), y ese verso sí que no es mío, sino de Shakespeare" (2014: 45). El escritor novísimo mantuvo una relación amorosa, apasionada y tormentosa, con un estudiante de la Complutense en 1981. La relación nominal de profesores, compañeros y poetas y las canciones de la época sitúan esta historia en un tiempo fácilmente reconocible así como por el 
rastro del tiempo del discurso, treinta y cuatro años más tarde, en la persona, el amor escrito:

Mi amor por Luis fue un amor sin resguardo, el más cierto, el más excitante y desequilibrante de mi vida, $y$, pese al devenir de dos años felices y tormentosos, el más perdurable. [...] Quizá el amor de Luis fue sólo un amor escrito. De ahí también su potencia, su atractivo para mí y su permanencia, ahora que somos viejos [...] y nuestras vidas tomaron sendas distintas [...] y sufriendo él la acometida del más amargo intruso, la enfermedad. (2014: 409).

Celos y recelos, reproches, traiciones, abandonos, desaires y desvelos mantienen en vilo y tensan esta valiente relación, evocada desde la vejez amenazada por la enfermedad, al "escribir sobre el pequeño andamiaje de las cartas que nos cruzamos (veinticuatro) el relato novelado y veraz de nuestra breve pero para mí al menos definitiva historia de amor" (2014: 407).

En resumen, la novela española más reciente continúa enraizada en el individualismo, en el tratamiento del yo y su entorno: la familia, la infancia, el recuerdo, los sentimientos..., ahormado con un estilo llano en unos y culturalista en sus periodos sintácticos e imágenes en otros. A un realismo psicologista decimonónico, de amplias pretensiones, enmarcado por la historia que trascendía la anécdota, espejo y testimonio, se contrapone otro de tono intimista y personal, en el que el autor atestigua la experiencia de lo cotidiano (Juan J. Millás y Fernando Aramburu), con protagonistas que exhiben sus vidas impudorosamente (Rafael Chirbes y Vicente Molina Foix), mediante la memoria y la autoficción (Marta Sanz y Luis Landero), con el relato de la historia personal (Antonio Muñoz Molina y Javier Cercas) o la celebración de más altos vuelos históricos (Arturo Pérez Reverte y Almudena Grandes). 


\section{Bibliografía}

\section{Novelas citadas}

Aramburu, F. (2016). Patria. Barcelona: Tusquets.

Cercas, J. (2001). Soldados de Salamina. Barcelona: Tusquets.

Cercas, J. (2017). El monarca de las sombras. Barcelona: Random House.

Chirbes, R. (2013). En la orilla. Barcelona: Anagrama.

Chirbes, R. (2016). Paris-Austerlitz. Barcelona: Anagrama.

Grandes, A. (2010). Inés y la alegría. Barcelona: Tusquets.

Landero, L. (2014). El balcón en invierno. Barcelona: Tusquets.

Millás, J.J. (2007). El mundo. Barcelona: Planeta (Premio Planeta 2007).

Molina Foix, V. y Cremades, L. (2014). El invitado amargo. Barcelona: Anagrama.

Muñoz Molina, A. (2004). Ventanas de Manhattan. Barcelona: Seix Barral.

Muñoz Molina, A. (2009). La noche de los tiempos. Barcelona: Seix Barral.

Muñoz Molina, A. (2013). Todo lo que era sólido. Barcelona: Seix Barral.

Muñoz Molina, A. (2014). Como la sombra que se va. Barcelona: Seix Barral.

Pérez-Reverte, A. (2007). Un día de cólera. Madrid: Alfaguara.

Pérez Zúñiga, E. (2016). No cantaremos en tierra de extraños. Barcelona: Galaxia Gutemberg.

Riera, C. (2013). Tiempo de inocencia. Madrid: Alfaguara.

Sanz, M. (2008). La lección de anatomía. Barcelona: RBA.

Vicent, M. (2010). Aguirre, el magnifico. Madrid: Alfaguara.

Vila-Matas, E. (2010). Dublinesca, Barcelona: Seix-Barral.

\section{Estudios}

Alberca, M. (2007). El pacto ambiguo. De la novela autobiográfica a la autoficción. Madrid: Biblioteca Nueva.

Alberca, M. (2017). La máscara o la vida. De la autoficción a la antificción, Málaga: Pálido fuego. 
Aramburu, F. (2018). "La primera patria de Fernando Aramburu". El Mundo, 19/02.

Caballé, A. (2018). “¿Inquisiciones?”. El País, 24/03/, 14.

Cercas, J. (2011). “La tercera verdad". Babelia, 25/06.

Chemin, A. (2013). "Fils, père de l'autofiction”. Le Monde/Culture et idées, 20/7.

Colonna, V. (2004). Autofiction et autres mythomanies littéraires. Paris: Tristam.

Díez, L.M. (1999). “Ficciones y emociones”. Insula, Muertes y porvenir de la novela, 634, 23.

Fernández Mallo, A. (2018). El Cultural, 2/III, 11.

Fortuño, S. (2011). "La poeticidad del microrrelato (a propósito de tres antologías)", Microcontos e outras microformas, 1-7. Braga: Universidade do Minho.

Gimferrer, P. (2018). "Poesía ininterrumpida”. Mercurio, 200, 22-23.

Goytisolo, L. (2016). "La narrativa en sus transformaciones". Babelia. El País, 5/II.

Grell, I. (2007). “Pourquoi Serge Doubrowsky n'a pu éviter le terme d'autofiction?" en J.L., Jeanelle et C. Violet (eds). Genèse et Autofiction. Louvain-la-Neuve: Academia, Bruylant.

Guelbenzu, J.Ma. (2014). El Cultural. 10/I.

Gullón, R. (1970). "La historia como materia novelable". Anales galdosianos, Vol. 23-35.

Izquierdo, J.Ma. (2000). "Memoria y Literatura en la narrativa española contemporánea”. Unos ejemplos, Anales, 3-4, 101-128.

Lecarme, J. (1994). “Autofiction: un mauvais genre?", Autofiction et Cie, Ritm, Paris, 6(I), 227-249.

Lejeune, Ph. (1975). Le pacte autobiografique, Paris: Éditions du Seuil.

Martín Nogales, J.L. (2011). “El cuento cambia de siglo”, en Nueva novela española,

La Página, 93-94, 67-76.

May, G. (1979). L'autobiographie, Paris: P.U.F.

Montero, R. (2018). Mercurio, 198, 7.

Mora, V.L. (2018). Mercurio, 200, 27. 
Muñoz Molina, A. (2014). "Quería contar la duración del amor", Cuadernos del Sur, Córdoba, 14/XII.

Navajas, G. (1993). “Una estética para después del posmodernismo: la nostalgia asertiva y la reciente novela española", Revista de Occidente, 143, 105-129.

Ortega y Gasset, J. $(1925,1975)$. Ideas sobre la novela, $9^{\mathrm{a}} \mathrm{ed}$. Madrid: Revista de Occidente.

Pozuelo, J.Mª. (2017). Novela española del siglo XXI. Madrid: Cátedra.

Santonja, G. (1993). La novela revolucionaria de quiosco 1905-1939. Madrid: Museo Universal.

Sanz, M. (2018). "El aire de los tiempos". Mercurio, 198, 14-15.

Sanz Villanueva, S. (2011). "Presente y futuro de la novela española" en Nueva novela española, La Página, 93/94, 3-4.

Sanz Villanueva, S. (2018). Un amor. El Cultural 26/II, 16.

Vargas Llosa, M. (2015). "Reflexiones de un escritor". Discurso de doctor honoris causa por la Universidad de Salamanca, 6/VII, $1-11$.

Vásquez, J.G. (2017). “'Berta Isla', libro del año”. Babelia, 16/XII, 3. Vicente, A. (2018). Babelia, 3/III, 9.

Vilas, M. (2018). "La doma del pudor", Babelia, El País, 1377, 2-3.

Villanueva, D. (1977). Estructura y tiempo reducido en la novela. Valencia: Biblioteca Filológica, Editorial Bello.

Zanón, C. (2017). “Teoría y práctica del best seller”. Babelia, 23/12. 